\title{
EL TSUNAMI QUE VIENE: EL ADVENIMIENTO DE LAS POLÍtICAS PÚBLICAS ORIENTADAS A MEJORAR LA EXPERIENCIA DEL TURISTA
}

\author{
Basilio Verduzco Chávez \\ Universidad de Guadalajara \\ basiliov@cucea.udg.mx
}

\begin{abstract}
Este artículo explora las implicaciones teóricas y prácticas que las políticas públicas, diseñadas para mejorar la experiencia del turista con su propia participación y la de otros involucrados, pueden tener en la planeación de destinos turísticos, en la construcción de capacidades gubernamentales y en la intervención de involucrados. Con este trabajo se pretende ofrecer elementos para una mejor comprensión de los diseños de políticas y de los procesos que impulsan la competitividad de los destinos turísticos y subrayar la necesidad de evitar políticas dirigidas a mejorar la experiencia del turista sin contar con los diseños adecuados para alcanzar la meta. El estudio combina revisión teórica y análisis de contenido de estudios especializados y diseños de política. Los principales hallazgos sugieren que la transición hacia políticas para la experiencia del turista requiere diseños consistentes con ese objetivo, pero también la consideración de los aspectos geopolíticos de la planeación de destinos turísticos, las relaciones de poder, la construcción de capacidades para los diseñadores e implementadores de política, y un enfoque adecuado para el manejo de conflictos y negociación.
\end{abstract}

Palabras clave: Política pública, economía de la experiencia, competitividad, geopolítica, negociación.

\section{The APPROACHING TSUNAMI: EMERGENCE OF PUBLIC POLICIES ORIEN- TED TOWARD ENHANCING THE EXPERIENCE OF TOURISTS}

There is an international trend on policy design towards the orientation of public policies for enhancing tourist experiences with the participation of tourists and other stakeholders. This article explores the theoretical and practical implications that this transition on policy design processes may have over tourist destination planning, government capacity building and public participation. The relevance of studying this transition resides on the need for a better understanding of public policy designs and the policy process aimed at boosting tourist destination competitiveness. The article is an alert call for those involved on policy design to avoid policies aimed at enhancing the tourist experience without the proper designs to achieve that goal. The study combines a survey of theoretical studies and content analysis of policy designs. The main findings of the study suggest the transition towards policies targeted to enhance tourist experience requires coherent designs, but also the consideration of geopolitical aspects of tourist destination planning, power relations, capacity building for policy designers, and the relevance of a proper approach for conflict resolution and negotiation.

Keywords: Public policy, experience economy, competitiveness, geopolitics, negotiation.

Fecha de recepción: 28 de noviembre de 2016. Fecha de aceptación: 12 de enero de 2017.

CÓMO CITAR: Verduzco-Chávez, B. (2017.) El tsunami que viene: el advenimiento de las políticas públicas orientadas a mejorar la experiencia del turista. Dimensiones Turísticas, 1(1), 81-109. https://doi.org/10.47557/IOVV6983 


\section{El tsunami que viene: el advenimiento de las políticas públicas orientadas \\ a mejorar la experiencia del turista}

\section{INTRODUCCIÓN}

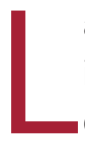

a búsqueda de experiencias en turismo tiene lugar en un mundo donde prolifera la inestabilidad y en el que se cuestiona el papel del Estado en la sociedad. Grandes procesos en el nivel internacional están sacudiendo el ámbito del turismo y erosionando, en consecuencia, la zona de confort de los diseñadores de política pública para destinos turísticos (Richards y Wilson, 2007). El turismo debe enfrentar lo que Pine y Gilmore (1998 y 2011) denominan la economía de la experiencia: un modelo de interacción socioeconómica que privilegia la satisfacción al detalle de preferencias ejercidas cada vez más cerca del ideal de racionalidad informada. Las tecnologías de información y los medios de comunicación contribuyen a la construcción de representaciones de destinos turísticos e influyen en las percepciones de los visitantes, en su disposición a involucrarse con otros actores y como coproductores de sus experiencias (Scarles y Lester, 2016).

En el mundo de la economía de la experiencia, la satisfacción de expectativas muy personales que anteceden al viaje reina sobre otros objetivos. De acuerdo con un reporte del Programa de Naciones Unidas para el Medio Ambiente y la Organización Mundial del Turismo (UNEP y wTo, 2005), 61 \% de los turistas de Estados Unidos busca experiencias de viaje en sitios con altos niveles de preservación (natural, histórica o cultural), 53 \% percibe que tiene una mejor experiencia cuando siente que aprende lo más que puede acerca del destino que visita, y 75 \% de los turistas británicos está de acuerdo con que su viaje debe incluir experiencias de cultura y comida local.

Los estudios sobre experiencias del turista intentan teorizar el consumo orientado a la experiencia al rescatar principios hedónicos del consumo que suponen la existencia de placer y satisfacción con base en sentimientos, fantasía y diversión. En ellos se resaltan los aspectos sensoriales del consumo que construyen a las experiencias como memorables (Sternberg, 1997; Quadri, 2012). Entre los aspectos que se consideran clave para el desarrollo de tales capacidades, se encuentran los nuevos conceptos de gobernanza y las estrategias de participación de múltiples actores en temas como desarrollo urbano, local, o gestión ambiental (Hsu, Inbakaran y George, 2013). ${ }^{1}$ Algunos trabajos han explorado las implicaciones de política de esta transición en ámbitos como la planificación de viajes (Cooper y Hall, 2008), el impulso a desarrollos locales (Kawato, 2009), la construcción de significados y experiencias emocionales (Jiricka, Salak, Eder, Arnberger y Pröbstl, 2010) o el papel de los eventos en el diseño de políticas (Dalonso, Lourenço, Remoaldo y Panosso Netto, 2014).

\footnotetext{
${ }^{1}$ La literatura sobre temas como, creatividad, gobernanza, participación pública, planeación estratégica en áreas como desarrollo urbano, desarrollo local o política ambiental es muy amplia (Richards y Wilson, 2007; European Union, 2011). En los trabajos abundan los estudios de caso sobre ciudades que han hecho importantes innovaciones en uno o más de los campos citados, como Curitiba en Brasil (Fukuda Hayakawa, 2010), Medellín y Bogotá en Colombia (Franco, 2015), Barcelona en España (Casellas, 2006 y Donaire y Galí, 2011), Ámsterdam en Holanda, etc. Discutir esos casos y los avances realizados en cada uno de los campos rebasa los objetivos de este trabajo.
} 


\section{B. Verduzco Chávez}

El artículo está organizado en cinco secciones. La primera explica el concepto de competitividad turística basada en experiencias; la segunda analiza las experiencias turísticas como objetivo de política pública; la tercera explora los avances y dificultades en el tránsito hacia políticas públicas facilitadoras de experiencias; la cuarta propone una caracterización de los diseños de política orientados a facilitar la construcción de experiencias; y la quinta examina los aspectos geopolíticos y de negociación que influyen en las posibilidades de impulsar políticas públicas orientadas al desarrollo de competitividad turística basada en experiencias.

\section{La COMPetitividad tURística en la eCONOMía de LA EXPERIENCIA}

La experiencia turística ha sido objeto de múltiples investigaciones. Laplante (1996) la define como algo esencialmente cultural y como una totalidad existencial mayor que la simple suma de todos los momentos y eventos que la forman. Sternberg (1997) propone una noción que oscila entre la búsqueda de la autenticidad y la reafirmación de expectativas. Oh, Fiore y Jeoung (2007) señalan que la experiencia es una construcción social fundamental tanto en la investigación turística como en el posicionamiento de los destinos turísticos. La transición hacia el turismo de experiencia es de alcance global. En su informe 2016, la Organización para la Cooperación y el Desarrollo Económicos (OCDE) destaca que “los clientes se están volviendo cada vez más experimentales, dispuestos a tratar nuevos productos, comidas y atracciones, y menos dispuestos a darle una segunda oportunidad a los destinos que ofrecen productos o servicios de una calidad pobre” (OECD, 2016, p. 63). Si bien persiste el modelo de turismo de masas, en la economía de la experiencia los activos demandados tienden a ser intangibles y poco convencionales. Esta circunstancia abre la puerta al problema de medir la calidad de las experiencias de los turistas y su relación con situaciones (tangibles o no) disponibles en los destinos turísticos, y a la definición de un nuevo papel para el Estado en la producción de experiencias.

Diversos estudios han empezado a hacer frente al primer problema, pero menos atención se ha dado al segundo. Oh et al. (2007) estudiaron la industria de los Bed and Breakfast, con un enfoque cualitativo y cuantitativo para analizar 24 elementos de la experiencia que fueron operacionalizados con una escala del tipo muy de acuerdo-muy en desacuerdo. Siguiendo las propuestas de Pine y Gilmore (2011), intentaron medir si el turista sintió que aprendió algo, si encontró estéticamente placentero su viaje, si obtuvo entretenimiento y si tuvo la sensación de haber escapado de su vida cotidiana. Billie (2010) señala que la experiencia descansa en 11 elementos que los consumidores consideran significativos: 1) un alto grado de concentración y enfoque; 2) el involucramiento de todos los sentidos; 3) una nueva percepción del tiempo, el cual se ha vuelto menos relevante; 4) la afectación emocional; 5) un proceso único que tiene un valor intrínseco para lo individual; 6) tener contacto con "lo verdaderamente real"; 7) hay la posibilidad de hacer y pasar por algo; 8) el sentido de ser parte de algo y de expectativa; 9) el sentido de control de la situación; 10) el balance entre el reto y la capacidad propia de hacerle frente, y 11) la existencia de una meta clara. 
Las empresas del sector han comenzado a introducir cambios a su infraestructura física, la imagen corporativa, los servicios de atención al cliente y el manejo de sus portales digitales. Domingo Álvarez, en su descripción del rediseño del sitio, aplicaciones móviles y quioscos de Aeroméxico, cita a Anko van der Werff, director ejecutivo de Ingresos de la empresa, quien explica que: "El propósito de este proyecto fue agilizar de manera real la experiencia de viajar del cliente, desde buscar un vuelo, hasta comprar y hacer el check in; al mismo tiempo buscamos inspirar a nuestros viajeros desde el momento de buscar un vuelo, capturando el sueño y la visión del destino que visitarán” (Álvarez, 2016, pp. 87-88).

En algunos destinos turísticos se escenifican experiencias mediante eventos o tours organizados en los cuales los turistas cuentan con la posibilidad de usar utensilios, sonidos, o participar en narraciones. Esto permite ver la ciudad desde otra perspectiva; se tiene acceso a información sobre las dimensiones culturales e históricas de una ciudad, así como el propósito de crear atmosferas en las cuales es más fácil que el turista pueda construir una experiencia memorable (Frochot y Batat, 2013). La diferencia entre hacer políticas para el turismo de masas y para el turismo de experiencia no radica en la existencia de diversidad de preferencias mostradas por los visitantes a un lugar, sino en el acoplamiento que se da entre lo que ofrece un lugar y las expectativas cambiantes, dinámicas, y las construcciones sociales mejor informadas que hacen los turistas de su visita a un sitio determinado.

Algunos estudios han iniciado la exploración de las implicaciones de política que tiene el turismo de experiencia, y han identificado innovaciones que abarcan nuevos modelos de gobernanza, planeación estratégica, participación, negociación, etc. (European Union, 2011). Nordin (2003) sugiere que los esfuerzos en el nivel de empresa son insuficientes pues el consumo demanda la participación del turista en su producción, y la experiencia se construye por las interacciones que el turista tiene en el destino turístico en general. Ashley, De Brine, Lehr y Wilde (2007) plantean que el desplazamiento del turista a consumir en un destino determinado implica que es necesario combinar prácticas comerciales e inversión local. Dalonso, Lourenço, Remoaldo y Panosso Netto (2014) analizan la influencia de eventos en la construcción de políticas públicas para la experiencia turística. En esta literatura se ha detectado la necesidad de que diversos involucrados cooperen para ayudar en la producción de experiencias turísticas.

El Estado puede impulsar la cooperación y la producción de los bienes públicos para favorecer la creación de experiencias. Henriksen y Halkier (2012) sugieren que la política pública debe usar una estrategia de desarrollo de producto para modificar los servicios. Desde una perspectiva de economía pública, la intervención del Estado en la generación de condiciones para experiencias se justifica por dos razones: el ambiente generador de experiencias memorables es un bien público y ninguna empresa particular puede producirlo; por otro lado, la calidad del servicio y de la atención recibida por un turista por parte de cada involucrado en la cadena de servicio tiene externalidades positivas y negativas y afecta el proceso general de generación de experiencias en el nivel de destino turístico. Oh et al. (2007) apuntan que la experiencia ofrecida por un destino abarca todos los eventos 


\section{B. Verduzco Chávez}

y actividades disponibles para el turista de tal modo que el Estado no solo funge como coproductor de las condiciones que facilitan las experiencias sino que debe garantizar atención adecuada en condiciones de incertidumbre con el propósito de reducir costos de transacción y riesgos que enfrentan los turistas en sus experiencias reales. ${ }^{2}$

Algunos analistas proponen que la experiencia abarca una serie de actividades que comprenden: a) la experiencia de preconsumo, en donde se ubican la búsqueda, la planeación, el hecho de pensar o soñar en el consumo, y la previsión o imaginación de la experiencia; b) la experiencia de compra, que tiene que ver con elegir, pagar, envolver el encuentro con el proveedor; c) la experiencia central de consumir, que apela a nociones de sensación, saciedad, satisfacción, transformación; d) la experiencia de recordar el consumo, que se forja con elementos para alimentar la memoria, historias contadas y que se ordena mediante procesos de clasificación de experiencias (Frochot y Batat, 2013).

En el pasado, las políticas públicas en turismo han privilegiado la acumulación de factores físicos y materiales mediante instrumentos de política industrial que procuran incrementar el flujo de inversiones y cambiar la mezcla de negocios que existen en un destino. Del lado de la demanda, las políticas se han enfocado a informar a los potenciales visitantes sobre la oferta disponible, a sugerir actividades posibles en los destinos promovidos y a mejorar la satisfacción de los consumidores (Wang y Meng, 2016). En la economía de la experiencia, el destino turístico pasa a ser visto como un espacio de múltiples identidades para desarrollar diversas actividades y por donde pasan diferentes personas (Andersen, 2015).

En medio de esta transición, algunos gobiernos han comprendido que la competitividad turística depende cada vez más de la capacidad de un destino turístico de ofrecer a los turistas las condiciones para construir experiencias. En el campo del turismo, hay un rezago en el entendimiento del papel de las políticas públicas en la gestión de destinos turísticos. La mayoría de los estudios sobre políticas de competitividad turística centran la investigación en la evaluación, pertinencia o alcances de la selección de instrumentos de política y procesos de implementación. Por años se pensó que los problemas de competitividad de los destinos estaban asociados a errores en la selección de instrumentos de política, a errores de implementación, a impactos sociales o ambientales imprevistos (Fayos-Solá, 1996; Ayuso, 2007; Velasco González, 2011; Costa, 2012). Las evaluaciones de resultados han ignorado la relación entre el diseño de tales instrumentos y la procuración de condiciones públicas para la construcción de experiencias como factor que puede influir en incrementar, mantener o erosionar la competitividad de un destino turístico. Esto es una deficiencia que merece ser atendida por los estudiosos de las políticas públicas y el desarrollo turístico.

\footnotetext{
${ }^{2}$ La complejidad de este reto ha quedado de manifiesto con el creciente uso de plataformas digitales para planificar viajes y contratar servicios, como son los casos de Airbnb o Uber, y la proliferación de incidentes de inseguridad asociados a su uso, lo cual obliga a una redefinición de ciertas funciones del Estado contemporáneo.
} 


\section{El tsunami que viene: el advenimiento de las políticas públicas orientadas \\ a mejorar la experiencia del turista}

\section{Experiencias tURísticas COMO OBJETO de poLítica PÚbLICA}

Como otras megatendencias, el avance hacia políticas públicas para el turismo de experiencia se construye a partir de ejemplos que ocurren en lugares pequeños o aparentemente periféricos. Las innovaciones y los diseños implementados en un lugar tienen que ver con las trayectorias y los horizontes planteados por los gestores de los destinos turísticos. Así, mientras que en Ámsterdam hay un acoplamiento entre el viajero que puede construir la expectativa de experimentar bares de mariguana y el distrito rojo (Jamal y Lelo, 2011) y la policía local que ha respondido, entre otras cosas, con advertencias de que no todas las prostitutas son efectivamente prostitutas, en el centro de Carlsbad, una ciudad que es ahora un suburbio localizado al norte de la zona metropolitana de San Diego, California, se gesta un proceso de acomodo dirigido a ofrecer "buenas experiencias" que busca acoplar una mayor densidad de uso de suelo con edificaciones turístico-comerciales y habitacionales, y la tarea de mantener el carácter pueblerino y rústico con el que arrancó esta ciudad a principios del siglo $x x$.

De tal acoplamiento surge el caso siguiente: en el sótano del restaurante The Land \& Water Co, ubicado en el corazón de Carlsbad Village, un distrito comercial y gastronómico, hay un establecimiento típico de la nueva economía del turismo del siglo xx. Por una puerta sin identificación clara se tiene acceso a un bar de cocteles que ofrece la experiencia de viajar a los años veinte del siglo pasado. Para ese fin, el bar ha revivido su pasado de la época de la prohibición y funciona como un lugar "secreto" que se abre al visitante si presenta una clave que se distribuye diariamente en Instagram. Para darle distinción a la experiencia se pide al visitante "mantener su mente abierta a la creatividad y la pasión" al ordenar lo que el cantinero ofrece cada día (Bryant et al., 2016).

Diversos estudios han empezado a identificar los retos de política que plantea la construcción de experiencias turísticas. Cooper y Hall (2008) argumentan que el turismo contemporáneo se basa en interrelaciones entre productores y consumidores de diversas experiencias, lo cual hace de los lugares donde se producen las experiencias el centro de interés de la planificación de viajes. Los consumidores persiguen nuevos significados. Lo que cada turista experimenta es único (Sharpley y Stone, 2012), pero los lugares pueden plantearse producir amalgamas de bienes y servicios sujetas a diferentes usos e interpretaciones. Los visitantes que buscan experiencias son definidos como un segmento del mercado en busca de actividades que tienen algún significado especial y alguna experiencia emocional personalizada (Jiricka et al., 2010). Kawato (2009) señala que esta transición abre posibilidades para impulsar procesos de desarrollo local en una gran diversidad de lugares pues los turistas en busca de experiencias tratan de encontrar respuestas a sus múltiples necesidades que les permita enriquecer su corazón y mente con situaciones cortadas a su propia medida.

Las variaciones en el concepto de competitividad turística introducidas por el paradigma de la economía de la experiencia se reflejan en la redefinición de los campos de acción pública para impulsar la competitividad turística en distintos niveles. En un nivel macro, 


\section{B. Verduzco Chávez}

esa competitividad está relacionada con las condiciones generales en las cuales tienen lugar los flujos de turistas, de inversión y los patrones de localización de empresas turísticas. Es decir, tiene que ver con aspectos macroeconómicos como la paridad monetaria entre el país sede y sus posibles mercados, la inflación y el nivel de precios, los niveles salariales, la productividad de las empresas turísticas, los niveles impositivos, los costos de la infraestructura (Blanke y Chiesa, 2009), la seguridad y certidumbre jurídica dada a los flujos y a las transacciones, la reciprocidad diplomática, etc. (Nordin, 2003). En otro nivel, la construcción de experiencias está vinculada con las condiciones socioeconómicas en las que se dan las inversiones o se desarrollan las visitas de los turistas en un lugar determinado, y, en un nivel más básico, están las condiciones microespaciales donde se llevan a cabo las interacciones sociales turista-comunidad receptora.

El enfoque tradicional de competitividad local, apoyado por organismos internacionales de desarrollo, consta de tres dimensiones clave dirigidas a la oferta: provisión de infraestructura, mejora de los servicios y reducción de los costos de hacer negocios. ${ }^{3}$ Esta trilogía de campos de acción es un problema para las agencias especializadas en política y un enfoque inadecuado para la competitividad turística basada en la posibilidad de desarrollar experiencias porque en este ámbito no es suficiente con un enfoque centrado en la oferta como se sugiere en la figura 1.

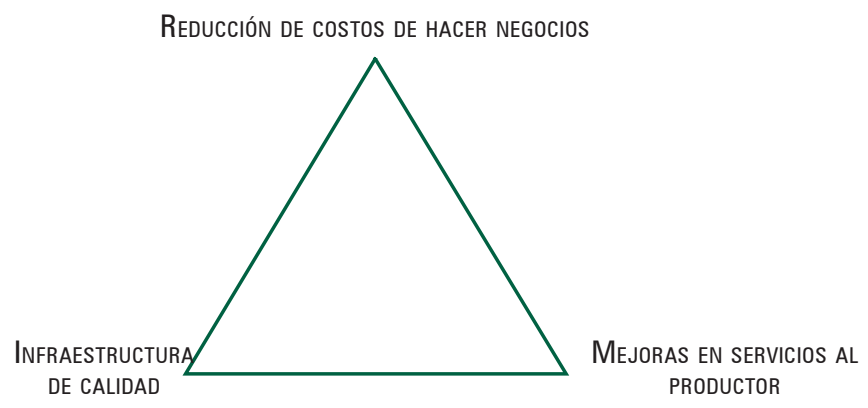

Fuente: Elaboración propia.

Figura 1. Modelo de campos de acción de política para la competitividad local centrado en la oferta

La noción de competitividad en turismo tiene una segunda capa centrada en la demanda, la cual está relacionada con el posicionamiento que logra un destino en las preferencias del turista y abarca dimensiones muy distintas a las anteriores (figura 2), es decir, la existencia de una oferta innovadora de bienes y servicios al consumidor, un ambiente urbano y natural propicio y sustentable para el desarrollo de experiencias memorables,

${ }^{3}$ Véase Banco Mundial: http://bit.ly/2b2DyOT 


\section{El tsunami que viene: el advenimiento de las políticas públicas orientadas \\ a mejorar la experiencia del turista}

y condiciones de conectividad, confiabilidad y confort en las instituciones que ofrecen certidumbre y seguridad a las interacciones sociales y buenas redes de infraestructura. En el turismo de experiencias, la competitividad de los destinos se construye sobre sus activos tangibles e intangibles que permiten al turista crear las experiencias memorables que lo llevan a repetir visitas, a promover por su cuenta las experiencias vividas y abrir con ello nuevas posibilidades de experiencias para otros visitantes. Las políticas públicas deben transitar a la redefinición de diseños de políticas posibilitadoras de la creación compartida de experiencias, lo cual tiende a abarcar el desarrollo de una agenda de inclusión social que se contrapone a los modelos de segregación comunes de los destinos turísticos convencionales.

En la figura 2 se agregan tres componentes adicionales al modelo de campos de acción de las políticas para la competitividad que responden a la necesidad de posicionar a un destino como espacio abierto a la coproducción de experiencias turísticas.

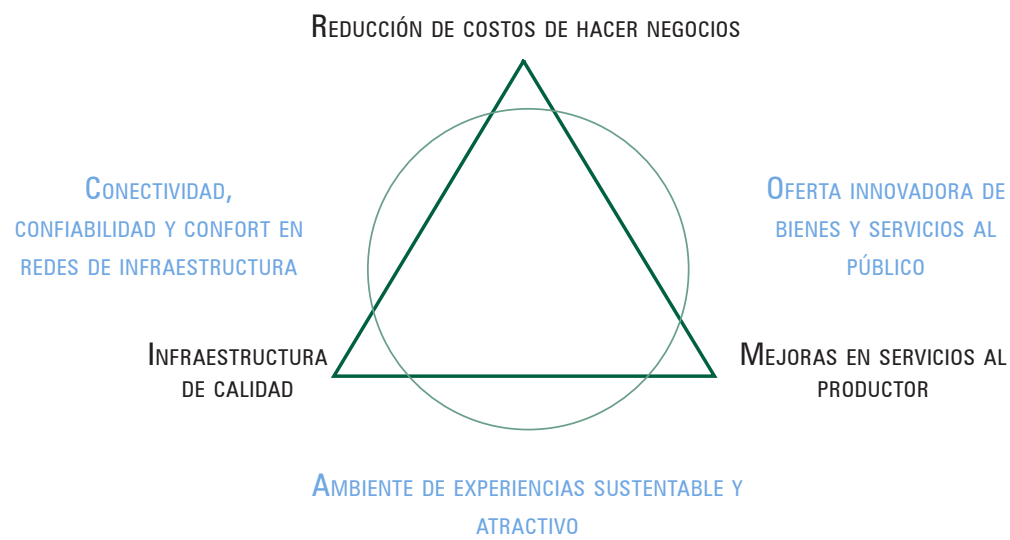

Fuente: Elaboración propia.

Figura 2. Modelo de campos de acción de política para la competitividad local centrado en la oferta y la demanda

El primer componente es la existencia de una oferta innovadora de bienes y servicios, lo cual implica la aceptación de nuevas modalidades formales e informales de oferta de esos bienes y servicios, como las plataformas tecnológicas que facilitan la accesibilidad a este tipo de oferta y la retroalimentación en tiempo real sobre el contenido y grado de satisfacción de esta experiencia (The Economist, 2015). El segundo elemento es la configuración de los espacios urbanos, rurales y naturales, así como instalaciones industriales, sitios históricos, regiones agroproductoras, etc., para convertirlos en escenarios posibilitadores de la coproducción de experiencias memorables para los turistas (Edensor, 2001; Pikkemaat, Peters, Bosberger y Secco, 2009; Franco, 2015; Mariani, 2016). Se trata de crear 


\section{B. Verduzco Chávez}

condiciones institucionales, de seguridad y de información que permitan a diversos tipos de visitantes utilizar los recursos en forma sustentable y tener certidumbre sobre los límites y restricciones a sus actividades concretas. Se trata de redefinir la relación entre cuerpo y lugar (Chronis, 2015).

Para el turista que busca experiencias memorables, es relevante saber que si ocurre algo desagradable o inesperado durante su viaje, el destino le ofrece respuestas a sus necesidades y hay responsables de dar seguimiento a sus observaciones o quejas incluso cuando ha regresado a su lugar de origen. Para los destinos turísticos es importante escenificar experiencias para turistas actuales sin poner en juego la posibilidad de su utilización para turistas futuros o para aquellos que buscan otro tipo de experiencias.

El tercer elemento se refiere a la posibilidad de contar con el respaldo institucional y la conectividad de redes de infraestructura a fin de facilitar desplazamientos y la comunicación como elementos articuladores de experiencias de los turistas (Boyne, Hall y Williams, 2003). Además de reducción de fricciones en la conectividad de sistemas de transporte y comunicación convencional (Moutinho, Ballantyne y Rate, 2011), el viajero contemporáneo aspira a contar en cada destino con la oportunidad de mantener contacto en tiempo real con sus redes sociales y con la confianza de que hay quien se hace responsable en el menor tiempo posible si llega a necesitar alguna atención personalizada (Scarles y Lester, 2016).

Desde una perspectiva holística, la competitividad de un destino turístico es creada tanto por políticas convencionalmente dirigidas al turismo (asignación de recursos para promoción, generación de equipamientos especializados, provisión de infraestructura urbana), como por acciones orientadas a facilitar la cooperación multilateral dirigida a la creación y preservación de bienes comunes (Molina Martínez, Ochoa Galván y Gil Lafuente, 2014). La ruptura con este sesgo de la política especial para turismo es compleja pero necesaria para impulsar la competitividad turística basada en experiencias.

\section{El tránsito hacia políticas públicas para la creación DE EXPERIENCIAS TURÍSTICAS}

En el tránsito hacia políticas públicas para la experiencia turística, los diseños específicos en cada lugar responden a diferencias contextuales que abarcan aspectos políticos habitados por actores reales, disponibilidad de recursos y oportunidades ofrecidas por el mercado global de turismo. Cada lugar enfrenta el problema de definir las políticas necesarias para facilitar la construcción de experiencias, o más directamente los diseños de política más adecuados para apoyar el surgimiento y/o consolidación de destinos abiertos a la construcción de experiencias memorables para una gran diversidad de turistas.

Lorentzen y Jeannerat (2013) señalan que el enfoque de la economía de la experiencia implica trasladar la atención de la producción al consumo, lo cual significa que debe atenderse a múltiples actores. Es decir, implica la participación de más involucrados. Ellos apuntan que las políticas deben procurar la producción de espacios para el consumo ya 
sea en distritos urbanos especializados o en espacios feriales dando lugar a enfoques de desarrollo local más integrales. Pero este tránsito no es un asunto sencillo. Si bien hay una amplia literatura sobre satisfacción del consumidor, el desarrollo de enfoques teóricos y metodológicos para hacer políticas públicas con orientación a la experiencia atraviesa por dificultades. Al escribir en torno al tema de la economía de la experiencia, Pine y Gilmore (1998) indican que las empresas deben mejorar sus ofertas para no atascarse en el nivel de ofrecer simples mercancías, sin embargo, no dan pistas claras sobre cómo las políticas públicas pueden ayudar a las empresas y, por lo tanto, a los destinos turísticos a avanzar a la producción de experiencias.

Por otra parte, la creación de indicadores sobre la calidad de las experiencias en un destino turístico se encuentra poco desarrollada. Kim, Brent Ritchie y McCormick (2012) usan una escala construida con indicadores que se refieren a siete dimensiones de la experiencia: hedonismo, frescura, cultura local, significancia, conocimiento, involucramiento y novedad. Empero, pocos destinos están preparados para hacer este tipo de mediciones o para explorar formas alternativas de diseñar políticas adecuadas a este tipo de turismo.

En esas circunstancias, prevalecen los estudios que dan cuenta de soluciones intermedias entre enfoques convencionales e innovaciones orientadas por la noción de economía de la experiencia. El reporte de la OCDE para 2016 señala que "la localización, capacidad, eficiencia y conectividad del transporte, pueden [...] jugar un papel muy importante en la manera como se desarrolla físicamente un destino, e influir significativamente en la movilidad de los visitantes y en la conectividad de las experiencias de los turistas dentro de sus destinos" (OECD, 2016, p. 63). Sin embargo, este tipo de estudio no orienta con claridad las dinámicas de diseño y no sugiere las características de los diseños de las políticas para apoyar la construcción de experiencias turísticas.

Al evaluar las experiencias en los países nórdicos, Billie (2010) identifica que si bien la economía de la experiencia resulta atractiva para introducir nuevas políticas públicas, el trabajo realizado ha estado más basado en la política que en el conocimiento. Allen y Brennan (2004) explican cómo la introducción del concepto de democracia a la forma de gobierno en Sudáfrica se ha usado para ofrecer la esperanza de mejores experiencias a turistas internacionales. No obstante, reconocen que la política pública no puede obligar a la adopción de una moralidad económica en los individuos, por lo que las autoridades a cargo de la política turística en KwaZulu-Natal, una de las regiones con mayor turismo en ese país, pueden diseñar políticas pero no tienen la posibilidad de hacer que los individuos se comporten conforme a las metas del programa, y concluyen que: "La gente necesita poder confiar en sus conciudadanos para actuar de una forma congruente con las políticas derivadas, legitimadas y reguladas en forma colectiva, antes de comprometerse a realizar conductas que apoyan dichos programas" (Allen y Brennan, 2004, p. 233).

Mohammed (2014) anota que, en 2006, Ghana definió como su objetivo proveer a los turistas experiencias de alta calidad, que fueran a la vez rentables para los involucrados del destino y no pusieran en juego la sustentabilidad del mismo. Los diseños introducidos procuraron mejorar la vida de los pobres y garantizar la sustentabilidad ambiental, incor- 


\section{B. Verduzco Chávez}

poraron la participación y el estímulo al papel del sector privado en el desarrollo turístico, y dieron preferencia a acciones que empataban con las habilidades laborales existentes.

Irlanda es un país que ha intentado transitar a una política de crecimiento turístico orientada a las experiencias. Su estrategia abarca diversas acciones, que incluyen el desarrollo de una marca amplia para la isla, que permite agrupar los activos en torno a paquetes de experiencias para visitantes a Gran Bretaña, como pueden ser "La vibra de la ciudad", "Revivir la historia", "Despertar los sentidos" o "Mantenerse activo". Por otro lado, se clasificó a los turistas como experimentadores con mayor o menor potencial de visita, para lo cual se identificaron tres tipos: "curiosos culturales", "buscadores de grandes escapes" y "creadores de energía social”, y se concluyó que la mercadotecnia debe hacer propuestas de experiencia focalizadas y relevantes. Otras acciones dirigidas a conformar y facilitar la construcción de experiencias incluyen la evaluación de impactos de nuevos desarrollos, la construcción de instalaciones para vacaciones en torno a actividades y el desarrollo de arquitectura de marca.

El estudio critica el enfoque de desarrollo de bienes de capital cuando señala:

El diseño de cualquier programa futuro de inversión en capital debe considerar la variedad completa de inversiones turísticas, que puede mejorar en lo general la experiencia del visitante. Por lo tanto el apoyo a la inversión en bienes de capital puede abarcar otros tipos de gasto, por ejemplo proyectos de tecnología de información que mejoran la calidad de la experiencia del visitante, así como gastos en el desarrollo de experiencias que agregan animación a un destino para los visitantes [y propone que] Los eventos seguirán siendo una parte importante de la oferta turística irlandesa, y el gobierno se asegurará de que existan las estructuras correctas para facilitar eventos con el fin de contribuir en forma efectiva a la calidad general de la experiencia del visitante [Department of Transport, Tourism and Sport, 2015, pp. 29 y 31].

Enfrentados a la necesidad de facilitar la creación de experiencias y atender preferencias mejor informadas, los diseñadores de las nuevas políticas de competitividad turística deben resolver el problema de abandonar los enfoques tecnocentristas para transitar hacia la institucionalización de la creación de experiencias donde el consumidor asume un papel central como coproductor de su propia experiencia en un escenario turístico determinado. Esto incluye la revisión de los modelos participativos propios de otros campos de planeación turística. Los problemas que afronta el diseñador de políticas turísticas son los siguientes:

- Las políticas deben diseñarse para escenarios locales contingentes. Es decir, no solo se enfrenta el problema de definir escenarios futuros mediante el análisis de tendencias locales, sino de variables que ocurren en el nivel global, y particularmente en los entornos donde se generan los principales flujos de turistas.

- Las políticas deben diseñarse para poblaciones-objetivo móviles. Las políticas para turismo deben tener en cuenta el carácter móvil de una buena parte de las poblaciones objetivo que es conformada por los flujos de turismo. 
El tsunami que viene: el advenimiento de las políticas públicas orientadas

a mejorar la experiencia del turista

- Los mecanismos participativos convencionales son inadecuados. El diseño de políticas turísticas demanda la innovación en materia de participación ciudadana considerando que los grupos a los que va encaminada no son residentes de los lugares a los cuales están dirigidas las políticas.

Un aspecto importante lo constituye la definición de las características de los diseños de política pública que es necesario adoptar para hacer frente al advenimiento de la competitividad turística basada en experiencias. En la siguiente sección se propone una caracterización fundamentada en la teoría del diseño de políticas.

\section{La CONSTRUCCIÓN DE diseños de poLítica PÚBLICA PARA LAS EXPERIENCIAS DE TURISTAS}

Los diseños de política contienen una serie de elementos que en conjunto permiten procurar grandes objetivos sociales (Schneider e Ingram, 1997). La tarea es compleja pues implica trascender la práctica de la mercadotecnia territorial orientada a la creación de marcas locales para avanzar hacia la política de escenificación de experiencias que tienen lugar en el nivel local (Fisker, 2015). Diseñar políticas para la competitividad turística basada en experiencias es una tarea que pone a prueba la capacidad de los gobiernos para redefinir todos los elementos de los diseños de política. A continuación se pueden señalar algunas lecciones derivadas de casos y estudios realizados en el ámbito internacional:

a) En el plano de la definición del problema, los diseños de política demandan un concepto de experiencia turística como una construcción social participativa, dinámica y en constante transformación. Este enfoque procura recomendaciones para facilitar el proceso de la creación de experiencias (Centre for Strategy \& Evaluation Services, 2013). Al criticar el enfoque que favorece a empresas en forma aislada e impulsar otro dirigido a la formación de clústeres, Porter (2007) muestra las limitaciones de pensar la hechura de políticas sobre la herencia de las políticas industriales convencionales. A pesar de su intento de creatividad, Porter identifica funciones para la política pública encauzadas principalmente a incrementar la oferta, lo cual incluye: inversión en bienes públicos de utilidad para las empresas, provisión de reglas, mecanismo de incentivos para capturar externalidades, ensamblaje de información sobre la integración de los clústeres. Porter imagina a gobiernos convocando a los participantes del clúster y como participantes activos en diálogo para identificar debilidades, crear incentivos para inversión colectiva, y como coinversionistas en instalaciones de uso colectivo. El turismo de experiencia demanda más que eso, para ir hacia procesos de escenificación de relaciones.

b) Las poblaciones objetivo de las políticas dirigidas a la construcción de experiencias caen dentro de tres grandes grupos: residentes locales como usuarios/constructores permanentes de las escenificaciones propuestas al turismo; negocios que ofrecen 


\section{B. Verduzco Chávez}

bienes y servicios a población y visitantes, y flujos de visitantes quienes se espera participen en la construcción de sus propias experiencias.

c) En lo referente a la definición de objetivos y metas, se necesita ajustar estas a lo que es objetivamente posible en determinadas circunstancias (Wang y Meng, 2016) y para impulsar dinámicas de diseño con la participación de múltiples involucrados en la creación de escenarios socioespaciales flexibles. Asimismo se reconoce la responsabilidad de los gobiernos como facilitadores y alentadores de la participación de una gran diversidad de grupos (UNEP y WTO, 2005).

d) En el campo de la definición de herramientas a utilizar, los estudios de turismo inspirados en la teoría de la economía de la experiencia solo han llegado a enunciar algunos aspectos de política pública que se consideran relevantes ante el advenimiento de este fenómeno. En su estudio, Arthur (2011) identifica como opciones posibles la organización de seminarios sobre innovación, el impulso al aprendizaje, la formación de redes de cooperación y la ampliación de redes para compartir conocimiento. Por su parte, Quadri (2012) menciona el papel de los incentivos financieros para promover ciertas formas de turismo, como el rural.

e) En cuanto al establecimiento de reglas contempladas en los diseños de política pública, la transición hacia el turismo de experiencias demanda instituciones flexibles con bajos costos de transacción, lo cual tiene lugar si los turistas, prestadores de servicios y ciudadanía en general asumen de manera voluntaria el cumplimiento de reglas, lo que garantiza procesos de implementación de menor costo (Halkier, 2009). Esta transición enfrenta la inercia de los sistemas estandarizados de control de la experiencia del turista que va desde la regulación comprensiva de uso del suelo en la ciudad, el manejo de los flujos de turistas y, en general, otros aspectos de las relaciones entre turistas y visitantes y los procesos de acumulación (Fainstein, Hoffman y Judd, 2003).

f) Los diseños demandan agentes y estructuras de implementación, abiertos a la experimentación, capaces de responder y hacer ajustes a sus rutinas para adaptarse a las necesidades cambiantes de los diversos flujos de turistas, y encauzados a facilitar la conformación de grupos de interés y segmentos de experimentación, respetuosos de los procesos de construcción de significados de las experiencias turísticas. Las estructuras y los agentes de implementación demandados por el turismo orientado a las experiencias son menos dirigidos desde arriba, guiados por funcionarios que cuentan con recursos para buscar los objetivos de la política y se basan en una mayor apertura a los intereses de otros actores (Rodríguez, Williams y Hall, 2014). Es decir, se trata de estructuras que favorecen la participación y la toma de decisiones descentralizadas, lo cual incrementa la capacidad de respuesta a las necesidades cambiantes de los flujos de turistas que participan en la creación de experiencias. Algunos obstáculos que se han encontrado en este sentido son la centralización de las administraciones públicas, la ausencia de coordinación y 
cohesión en la industria del turismo o entre agencias del gobierno, y la falta de información (Tosun, 2000).

g) Finalmente, respecto a las racionalidades y supuestos, o a la búsqueda de grandes justificaciones sociales, políticas y culturales para la política pública, los diseños de política para el turismo experimentador necesitan trascender de las nociones de competitividad turística focalizada en el ambiente de negocios turísticos para llegar a la competitividad basada en la integralidad de la escenificación socioespacial de la experiencia del turista. El movimiento hacia un turismo encaminado a la construcción de experiencias demanda una redefinición de las dinámicas de diseño de las políticas y de la orientación de tales diseños. Como señala Lengkeek (2002), las políticas deben hacer justicia a diferentes modalidades de experiencia. En un nivel más general, esto implica producir espacios y ciudades turísticas que ofrezcan un escenario propicio para realizar múltiples actividades, así como condiciones para expandir las libertades y las opciones de vida de pobladores y visitantes.

Más que encauzar su trabajo a organizar la visita del turismo como una relación eficiente entre un clúster de prestadores de servicios y una masa de turistas segmentada en función de sus características sociodemográficas, los agentes y estructuras de implementación deben colaborar en la conversión del tour como una interacción social flexible que ofrece múltiples oportunidades al turista para acceder a diferentes estilos de vida, condiciones sociourbanas, vivencias culturales, gastronomías, y ser parte de la procuración de un mejor ambiente. De acuerdo con un reporte de Salman (2008), para ofrecer condiciones para la construcción de experiencias es necesario posicionar la marca de la ciudad, lo cual implica "convertir la ciudad en un lugar donde la gente quiere vivir, trabajar y visitar” (http:/ /bit.ly/2wKXYf2). Kavaratsis (2017) propone que la experiencia turística es una experiencia personal, por lo que se da en un lugar donde todos los actores involucrados interactúan y construyen sus propios significados. Los actores locales cumplen un papel importante antes, durante y después de la visita.

Una muestra ilustrativa de la transición de las políticas públicas convencionales a políticas orientadas a la experiencia del turismo es lo observado en el distrito gastronómico de Chapultepec en la ciudad de Guadalajara. Ahí el gobierno local inició con acciones orientadas por conceptos convencionales de competitividad dirigidas a la producción de ambientes de inversión, pero recientemente ha avanzado a políticas encaminadas a la experiencia del turista. Para propósito de este análisis, las políticas se dividen en dos etapas: una que abarca una serie de proyectos y políticas de rescate y remozamiento de banquetas y mobiliario urbano en Paseo Chapultepec -una avenida en el centro-poniente de Guadalajara que hasta mediados del siglo xx fue uno de los barrios residenciales más acaudalados-, y una segunda etapa que cubre los esfuerzos más focalizados en crear un escenario para la experiencia gastronómica de corte tradicional, la cual se concentra sobre el corredor gastronómico de la calle López Cotilla que cruza el Paseo Chapultepec, casi a la mitad de la extensión del mismo. 


\section{B. Verduzco Chávez}

Como se expone en el cuadro 1, es posible notar con claridad cómo los gobiernos estatal y municipal de Guadalajara han intentado transitar del enfoque dirigido a la producción de bienes a una estrategia de escenificación de la experiencia gastronómica como rasgo distintivo de este distrito urbano, que es la principal apuesta de la entidad para capitalizar la transición de los destinos turísticos de la economía de Jalisco hacia la economía de la experiencia.

En la primera etapa, las políticas dirigidas al Paseo Chapultepec estuvieron guiadas por un enfoque de urbanismo y obra pública e hicieron uso de herramientas y reglas convencionales que ponen en manos del gobierno la responsabilidad de controlar la construcción del espacio urbano turístico con la intención de aprovechar su valor histórico y estético. Un exfuncionario describe así tal orientación urbanística:

el arreglo de esta avenida [es un] Garbanzo de a libra -y presume- allí está la obra terminada [...] su vocación principal es la recreativa: es un pequeño boulevard, o una rambla, por la que la población puede pasear, descansar, sombrearse; los niños tienen espacio para jugar y los mayores para cuidarlos. El ejercicio del paseo citadino, con el reconocimiento que así se genera entre la población, y de ésta con su entorno, es una función esencial para el arraigo de una identidad compartida. [...] Se le dieron dos metros más de ancho al camellón, a costa del espacio para los coches, y se rehízo toda su infraestructura, se plantaron centenares de árboles y se introdujo nueva y apropiada jardinería en los costados [Palomar Verea, 2014, s. p.].

La obra realizada es descrita por este funcionario como un caso exitoso de renovación urbana y dotación de infraestructura y equipamiento, pero bajo el supuesto arquitectónico de que la forma guiaría la función, y cuando el espacio fue carnavalizado y apropiado por grupos sociales de medios y bajos ingresos que fueron construyendo sus propias experiencias y vivencias sobre el espacio urbano, la racionalidad funcionalista y el clasismo se vieron vulnerados. El choque de orientaciones y resultados de la política pública es expuesto entonces de la siguiente manera:

Pero ahora sucede que Lafayette/Chapultepec está padeciendo fuertemente su propio éxito. Los camellones se han venido usando para todo tipo de cosas, unas favorables y otras no. Los conciertos masivos, en particular, son incompatibles con el espacio. Desbordado, éste sufre de graves deterioros en varios órdenes. El ruidajal en primer lugar: si se quiere que la zona se siga habitando y aun que llegue más gente a vivir allí, es indispensable guardar un buen nivel de calidad de vida. Ni las hordas ni los tamborazos a todo volumen ni las grafiteadas y el basural posteriores ni el simple congestionamiento causado deberían ser tolerados. Los continuos maltratos de los "escatos" y sus interminables tablazos deben ser reglamentados. Los vendedores ambulantes puestos en orden. Las reglas de tránsito respetadas (desde el principio se prohibieron las vueltas a la izquierda para dar así preferencia a los paseantes que cruzan de un camellón a otro; ahora es la anarquía). Después de graves problemas, la seguridad ha mejorado mucho y la policía montada ha sido un éxito (incluso desde el punto de vista estético); este aspecto es obviamente fundamental [Palomar Verea, 2014, s. p.]. 


\section{El tsunami que viene: el advenimiento de las políticas públicas orientadas a mejorar la experiencia del turista}

Según este autor, para que la política pública logre sus auténticos objetivos, el Estado debe imponer el orden en forma vertical, debe restablecer la segregación en el uso del espacio urbano y matizar el ejercicio de la autoridad con diseños estilizados.

Por su parte, la etapa inaugurada bajo el concepto de Saborea Guadalajara exalta la posibilidad de la experiencia que combina caminar, comer y escuchar música popular, en donde la gestión de la experiencia se basa en una mayor participación de prestadores de servicios y visitantes y con una mayor flexibilidad en el diseño de las propias experiencias. Si bien se habían hecho labores de remozamiento previamente, la reorientación hacia la experiencia tuvo una inauguración formal el 25 de abril de 2016 para coincidir con el Tianguis Turístico celebrado en la ciudad.

En su inauguración, involucrados clave en el proyecto lo definieron como una iniciativa que permite "activar estratégicamente espacios que promuevan la convivencia donde el ciudadano se apropie de los espacios públicos”, "un experimento” y una oferta que cuenta con "variedad gastronómica de 11 países" que tiene mucho que ofrecer (Redacción Proyecto Diez, 2016, s. p.). La invitación oficial del ayuntamiento distribuida en redes sociales describe esta experiencia del siguiente modo:

Te invitamos a vivir "Saborea Guadalajara" todos los jueves en punto de las 6 de la tarde y hasta la medianoche en el Corredor López Cotilla (entre Francisco Javier Gamboa y Chapultepec). Tapatíos y visitantes son bienvenidos para disfrutar la oferta gastronómica que el Corredor ofrece. $^{4}$

El contraste entre ambas orientaciones y entre las interpretaciones de estas dos etapas de una política para un mismo distrito urbano-gastronómico turístico muestra cómo las ciudades deben pasar por un proceso de aprendizaje y experimentación en el diseño de políticas públicas turísticas, que no por urgente debe ser improvisado.

Los diseñadores de políticas deben distinguir las políticas convencionales que ven los destinos turísticos como proveedores de infraestructura, bienes y servicios específicos, de aquellas dirigidas por conceptos integrales de satisfacción de expectativas y preferencias (Ljunggren, 2012). Es decir, deben buscar políticas que favorecen la autenticidad de los bienes y servicios producidos, procuran mejorías de calidad, consistencia, el aseguramiento de la sustentabilidad, y la formación de redes, mediante un énfasis en los aspectos creativos de la producción (OECD, 2012), dando lugar a procesos de diferenciación de productos o servicios con mejores combinaciones de recursos locales (Sidali, Kastenholz y Bianchi, 2013).

En suma, en la economía de la experiencia los diseños que influyen en la competitividad de un destino turístico son aquellos que sirven a los involucrados para establecer una plataforma donde los visitantes pueden encontrar coherencia entre sus preferencias y expectativas iniciales y sus vivencias reales.

\footnotetext{
${ }^{4}$ Comentario plasmado en Facebook del Gobierno de Guadalajara (2016). Recuperado de https://etrigg.com/event/ saborea-guadalajara/27743000/
} 


\section{B. Verduzco Chávez}

Cuadro 1. Dos etapas del diseño de política para el desarrollo de un distrito urbano gastronómico-turístico

\begin{tabular}{|c|c|c|}
\hline Elemento de diseño & Etapa 1. Construyendo el Paseo Chapultepec & $\begin{array}{l}\text { Etapa 2. La experiencia de Saborea } \\
\text { Guadalajara }\end{array}$ \\
\hline Definición del problema & Problema de imagen urbana. & $\begin{array}{l}\text { La oferta gastronómica necesita } \\
\text { consolidarse y el barrio debe ofrecer } \\
\text { una experiencia auténticamente tapatía } \\
\text { a los visitantes. }\end{array}$ \\
\hline Poblaciones objetivo & $\begin{array}{l}\text { Habitantes y propietarios de la zona. Dueños } \\
\text { de todo tipo de establecimiento comercial y de } \\
\text { servicios. Población joven de ingresos medios y } \\
\text { altos de la Zona Metropolitana de Guadalajara. } \\
\text { Visitantes a la ciudad que buscan espacios de } \\
\text { entretenimiento nocturno de corte familiar y } \\
\text { juvenil. }\end{array}$ & $\begin{array}{l}\text { Habitantes de la ciudad que procuran } \\
\text { una diversidad de oferta gastronómica. } \\
\text { Turistas y visitantes a la Zona } \\
\text { Metropolitana de Guadalajara que } \\
\text { buscan experiencias de gastronomía } \\
\text { diversa y oferta auténticamente } \\
\text { regional. Propietarios de restaurantes } \\
\text { y bares. }\end{array}$ \\
\hline \multirow[t]{4}{*}{ Objetivos y metas } & $\begin{array}{l}\text { Consolidar el paseo como centro de } \\
\text { entretenimiento y destino de paseos nocturnos. } \\
\text { Unificar la imagen urbana. }\end{array}$ & $\begin{array}{l}\text { Consolidar la oferta gastronómica, } \\
\text { fortalecer la identidad y diversidad } \\
\text { gastronómica del distrito. }\end{array}$ \\
\hline & \multirow[t]{3}{*}{ Mayor intensidad en el uso del suelo. } & $\begin{array}{l}\text { Posicionar a Guadalajara ante el } \\
\text { turismo internacional como un destino } \\
\text { gastronómico. }\end{array}$ \\
\hline & & $\begin{array}{l}\text { Hacer más atractivos los } \\
\text { desplazamientos peatonales. }\end{array}$ \\
\hline & & $\begin{array}{l}\text { Impulsar opciones de movilidad no } \\
\text { motorizada. }\end{array}$ \\
\hline \multirow[t]{6}{*}{ Herramientas } & $\begin{array}{l}\text { Remodelación de banquetas y superficie de } \\
\text { rodado. }\end{array}$ & $\begin{array}{l}\text { Ampliación de banquetas sobre la calle } \\
\text { López Cotilla. }\end{array}$ \\
\hline & $\begin{array}{l}\text { Rescate/introducción de elementos identitarios } \\
\text { de la Guadalajara "tradicional". }\end{array}$ & $\begin{array}{l}\text { Dotación de mobiliario urbano (bancas) } \\
\text { sobre banquetas ampliadas. }\end{array}$ \\
\hline & \multirow[t]{4}{*}{ Alumbrado público. } & $\begin{array}{l}\text { Conversión de la calle López Cotilla en } \\
\text { zona de velocidad reducida. }\end{array}$ \\
\hline & & Construcción de carril de bicicletas. \\
\hline & & $\begin{array}{l}\text { Organización de un evento semanal } \\
\text { de gastronomía, denominado Saborea } \\
\text { Guadalajara. }\end{array}$ \\
\hline & & Cierre temporal de la calle. \\
\hline \multirow[t]{5}{*}{ Reglas } & \multirow{2}{*}{$\begin{array}{l}\text { Revisión/actualización de planes parciales de } \\
\text { desarrollo urbano. }\end{array}$} & Control de velocidad de circulación vial. \\
\hline & & Restricción de circulación sobre carril \\
\hline & \multirow{2}{*}{$\begin{array}{l}\text { Autorización formal e informal de } \\
\text { modificaciones a fincas y giros comerciales y } \\
\text { de servicios. }\end{array}$} & exclusivo para bicicletas. \\
\hline & & \multirow{2}{*}{$\begin{array}{l}\text { Participación libre de los } \\
\text { establecimientos gastronómicos. } \\
\text { (Cada restaurante promueve su propio } \\
\text { concepto de comida y experiencia.) }\end{array}$} \\
\hline & $\begin{array}{l}\text { Organización de eventos de orientación } \\
\text { recreativo-cultural. }\end{array}$ & \\
\hline
\end{tabular}




\section{El tsunami que viene: el advenimiento de las políticas públicas orientadas}

a mejorar la experiencia del turista

Cuadro 1. Dos etapas del diseño de política para el desarrollo de un distrito (finaliza)

\begin{tabular}{|c|c|c|}
\hline Elemento de diseño & Etapa 1. Construyendo el Paseo Chapultepec & $\begin{array}{l}\text { Etapa 2. La experiencia de Saborea } \\
\text { Guadalajara }\end{array}$ \\
\hline \multirow{4}{*}{$\begin{array}{l}\text { Agentes y estructuras } \\
\text { de implementación }\end{array}$} & & \multirow{2}{*}{$\begin{array}{l}\text { Dirección de Turismo del Ayuntamiento } \\
\text { de Guadalajara }\end{array}$} \\
\hline & Dirección de Obras Públicas & \\
\hline & Dirección de Turismo & Secretaría de Vialidad \\
\hline & Dirección de Cultura & Propietarios de restaurantes \\
\hline $\begin{array}{l}\text { Racionalidades y } \\
\text { supuestos }\end{array}$ & $\begin{array}{l}\text { Ante el abandono del centro de la ciudad y la } \\
\text { transición de esta zona habitacional de altos } \\
\text { ingresos con orígenes a finales del siglo xIx } \\
\text { y primera mitad del xx, la ciudad necesita } \\
\text { un espacio que concentre oportunidades de } \\
\text { recreación y entretenimiento nocturno. }\end{array}$ & $\begin{array}{l}\text { La consolidación del distrito } \\
\text { gastronómico es útil para fortalecer la } \\
\text { posición de Guadalajara como distrito } \\
\text { gastronómico en el nivel nacional e } \\
\text { internacional. La localización del distrito } \\
\text { respecto a las zonas hoteleras de la } \\
\text { ciudad y a Expo-Guadalajara, aunada } \\
\text { al valor patrimonial de algunas fincas } \\
\text { de la zona, le da ventaja competitiva } \\
\text { en la construcción de la experiencia } \\
\text { gastronómica del visitante. }\end{array}$ \\
\hline
\end{tabular}

Fuente: Elaboración propia.

\section{Geopolítica y negociación en el diseño de políticas PARA LA EXPERIENCIA TURÍSTICA}

Ante el advenimiento de políticas orientadas a la creación de experiencias turísticas memorables es necesario reconocer las limitaciones geopolíticas y los retos de negociación. Los tres aspectos más importantes son las relaciones de poder existentes en los distintos territorios, el grado de centralismo o policentrismo que hay en las estructuras de diseño e implementación de las políticas turísticas y los escenarios de conflicto y negociación en los que se dan los procesos de diseño e implementación de políticas.

\subsection{Territorio, relaciones de poder y experiencias turísticas}

El turismo es a la vez manifestación y resultado de relaciones geopolíticas complejas que se producen en distintos espacios. Los destinos pueden ser vistos como unidades espaciales socialmente construidas que tienen lugar dentro de esferas de poder (Saarinen, 2004). Tanto en el nivel internacional como en el doméstico, el desarrollo de políticas públicas para la construcción de experiencias turísticas tiene un componente geopolítico cuyo primer elemento es la manera como se articulan las relaciones de poder en el territorio.

En el ámbito internacional, las posibilidades que tienen los países de incursionar en el turismo de experiencias están determinadas por su estatus dentro de las relaciones 


\section{B. Verduzco Chávez}

geopolíticas existentes y por las libertades a las que puede aspirar un turista en algún destino. Las relaciones geopolíticas influyen en aspectos estructurales como las facilidades otorgadas por un país a los ciudadanos de los demás países, lo cual moldea la experiencia de viaje desde su propia planeación en cuestiones como la obtención de visas o permisos especiales, y se extiende a otras durante y posteriormente al viaje, por ejemplo la duración de las estancias, el uso de moneda, el respaldo consular en caso necesario y el seguimiento dado a aspectos como quejas, sanciones o inconformidades de los turistas con algún involucrado encontrado durante su viaje. La geopolítica contemporánea produce situaciones como las relaciones entre China, Taiwán y Hong Kong, en donde las movilidades del turismo se entrelazan con las formas cambiantes de soberanía, la territorialidad y el establecimiento de fronteras (Rowen, 2016). Las relaciones geopolíticas influyen en la configuración de identidades (Daher, 2007) y, por lo tanto, en la construcción de la oferta y el establecimiento de relaciones especiales entre países respondiendo a afinidades étnicas (Yang y Wall, 2014), herencias coloniales (Keen y Tucker, 2012) o de dominio militar (Rech, 2015; Beeton, Yamaura y Seaton, 2016), o por afinidad ideológica o religiosa (Cohen-Hattab y Shoval, 2015).

Adicionalmente, la experiencia de los turistas no es ajena a las condiciones de incertidumbre e inseguridad originadas por guerras, terrorismo, o situaciones de emergencia ocasionadas por accidentes o desastres naturales. Las experiencias son moldeadas por los grados de cooperación entre países para atender este tipo de circunstancias o para otorgar facilidades de visita o las que se brindan a las empresas multinacionales para invertir, repatriar ganancias y rendir cuentas en aspectos ambientales, laborales o fiscales. Como señalan Allen y Brennan (2004), el turista internacional es un ciudadano del mundo que se interesa en los cambios políticos y su experiencia turística está mediada por la agenda política contemporánea.

Bloqueos carreteros, asalto a unidades de transporte, violencia descontrolada y una gran cantidad de conflictos socioambientales en los destinos turísticos muestran que, en el ámbito doméstico, las vivencias de los turistas se ven afectadas de forma cotidiana por las relaciones de poder existentes en el nivel nacional, regional o local, y su influencia en la diversidad de oferta de bienes y servicios, de las condiciones en las que se ofrecen los servicios y de los grados de responsabilidad que asumen los prestadores de servicios y oferentes de bienes frente a las necesidades e inconveniencias que puede enfrentar un turista durante su visita.

Las relaciones de poder condicionan el acceso a recursos, bienes y servicios que otros necesitan (Hazra, Fletcher y Wilkes, 2014). En el caso de México, las manifestaciones locales del impacto de las relaciones de poder en la experiencia de los visitantes se puede constatar en casos como los siguientes: los conflictos magisteriales que de manera recurrente se registran en Oaxaca, lo que se manifiesta en cancelación de vuelos o corridas de autobuses, bloqueos de carreteras y toma de espacios públicos o sitios con valor turístico; los bloqueos que hacen los taxistas en lugares como Puerto Vallarta en contra de otras opciones de movilidad de los visitantes, y la influencia de los monopolios de taxistas que controlan la transportación terrestre en los aeropuertos del país. 


\section{El tsunami que viene: el advenimiento de las políticas públicas orientadas}

a mejorar la experiencia del turista

Más aún, el turismo nacional se ve fuertemente afectado por la estrategia de soberanía graduada implementada por el gobierno, lo cual se ha reflejado en grados diferenciados en la oferta de seguridad por parte del Estado a sus visitantes, dando lugar a escenarios de inseguridad, crimen y zonas y sitios altamente protegidos.

\subsection{Policentrismo y estructuras de implementación}

La experiencia turística es moldeada por los niveles de centralismo observados en las estructuras de implementación de la política pública. El grado de descentralización es importante porque con ello se determinan competencias para decidir sobre la asignación de recursos, los alcances de la política y la posibilidad de lograr economías de escala o de presentar opciones de construcción de experiencias a los visitantes.

La decisión sobre la estructura de diseño e implementación de la política turística no es solo técnica, tiene también un fuerte contenido geopolítico y revela el estado que guardan las relaciones de poder en un régimen, entre grupos de poder y entre los centros políticos y sus zonas periféricas. Para ser competitivos, la mayoría de los países, sobre todo aquellos cuya economía depende más del turismo, ha optado por generar estrategias graduadas de competitividad turística consistentes en posicionar algunas regiones, olvidándose de lo que ocurre en las regiones definidas como no prioritarias. Esa selección no siempre corresponde a condiciones concretas locales sino a conexiones que tienen los grupos de interés regional en el diseño de la política pública nacional.

Los gobiernos centrales y gobiernos locales o regionales de las áreas turísticas tradicionales encuentran que es más sencillo resolver cualquier diferendo que pueda existir entre ellos para hallar un arreglo de colusión que permita seguir canalizando los recursos públicos a las mismas regiones. En el cuadro 2 se presenta un indicador de esta tendencia, pues muestra que en la selección de presidente de las comisiones de Turismo en el Congreso de la Unión prevalece no tanto la orientación partidista o la capacidad sino el origen del representante. Normalmente se privilegia a aquellos que han tenido alguna experiencia de gobierno o representación local en municipios con una base económica turística consolidada.

El uso de modelos centralistas de diseño e implementación de políticas tiene dos consecuencias perversas para el proceso de construcción de experiencias. Por una parte, facilita la introducción de sesgos en el arrastre de marcas. Este problema se manifiesta de dos maneras: la primera tiene que ver con los efectos perversos de asociar el nombre de un destino turístico a una marca más amplia que ha sufrido el desgaste por circunstancias fuera del control de los diseñadores de la política turística, como ha ocurrido en los centros turísticos mexicanos con el desgaste de la marca país debido a la inseguridad registrada en México en los últimos años; la segunda está relacionada con los efectos concentradores de las marcas apoyadas centralmente cuyos beneficios tienden a concentrarse en los centros turísticos convencionales. 


\section{B. Verduzco Chávez}

Cuadro 2. Perfil profesional y político de los presidentes de la Comisión de Turismo del H. Congreso de la Unión, 2000-2016

\begin{tabular}{|c|c|c|c|}
\hline Legislatura & Presidente & Partido & Experiencia \\
\hline $\begin{array}{l}\text { LXIII } \\
(2015-2018)\end{array}$ & $\begin{array}{l}\text { Gretel Culin } \\
\text { Jaime }\end{array}$ & PAN & $\begin{array}{l}\text { Electa por representación proporcional. Licenciada en } \\
\text { Comunicación Social. Fue previamente regidora en Manzanillo, } \\
\text { Colima y diputada local en Colima. }\end{array}$ \\
\hline $\begin{array}{l}\text { LXII } \\
(2012-2015)\end{array}$ & $\begin{array}{l}\text { Rodolfo Dorador } \\
\text { Pérez Gavilán }\end{array}$ & PAN & $\begin{array}{l}\text { Electo por representación proporcional, maestría y licenciatura } \\
\text { en Derecho. Funcionario del partido, fue diputado federal 2002- } \\
2003 \text { y senador } 2006-2012 \text {, delegado del IMSS y funcionario de la } \\
\text { Presidencia con el presidente Vicente Fox. }\end{array}$ \\
\hline $\begin{array}{l}\text { LXI } \\
(2009-2012)\end{array}$ & $\begin{array}{l}\text { Carlos Manuel } \\
\text { Joaquín } \\
\text { González }\end{array}$ & PRI & $\begin{array}{l}\text { Electo por mayoría relativa en Quintana Roo. Contador público } \\
\text { con diplomado en Alta Dirección. Antes de este cargo fue } \\
\text { presidente municipal de Solidaridad (Cancún), tesorero y } \\
\text { funcionario de la Secretaría de Turismo de Quintana Roo. }\end{array}$ \\
\hline $\begin{array}{l}\text { LX } \\
(2006-2009)\end{array}$ & $\begin{array}{l}\text { Amador } \\
\text { Campos Aburto }\end{array}$ & PRD & $\begin{array}{l}\text { Electo como diputado por mayoría relativa en el estado de } \\
\text { Guerrero. Fue presidente municipal de Teniente José Azueta } \\
\text { (Zihuatanejo), consejero estatal del PRD en Guerrero. Estudió } \\
\text { secundaria y fue presidente de la asociación ganadera local de } \\
\text { Zihuatanejo. }\end{array}$ \\
\hline $\begin{array}{l}\text { LIX } \\
(2003-2006)\end{array}$ & $\begin{array}{l}\text { Francisco } \\
\text { Xavier López } \\
\text { Mena }\end{array}$ & PAN & $\begin{array}{l}\text { Electo por representación proporcional, fue candidato del PAN a } \\
\text { la Gubernatura de Quintana Roo, presidente del partido en esa } \\
\text { entidad, licenciado en Derecho y diplomados en Alta Dirección y } \\
\text { Derecho Comercial, amplia experiencia empresarial en bancos, } \\
\text { empresas de transporte y agencias de viajes. }\end{array}$ \\
\hline $\begin{array}{l}\text { LVIII } \\
(2000-2003)\end{array}$ & $\begin{array}{l}\text { Jaime Arturo } \\
\text { Larrazabal } \\
\text { Breton }\end{array}$ & PRI & $\begin{array}{l}\text { Electo por mayoría relativa en Oaxaca. Estudió Arquitectura, fue } \\
\text { secretario de Desarrollo Urbano y secretario de Salud en Oaxaca. } \\
\text { Fue representante en la Asamblea Legislativa del D.F., candidato } \\
\text { independiente al gobierno municipal de Oaxaca, y miembro del } \\
\text { Consejo Político del PRI. }\end{array}$ \\
\hline
\end{tabular}

Fuente: Elaboración propia con datos del Sistema de Información Legislativa. http://sil.gobernacion.gob.mx//

El segundo problema es el surgimiento de barreras de entrada no convencionales. El turismo resulta un campo de política pública atractivo para los tomadores de decisiones por las bajas barreras de entrada. Sin embargo, la incursión efectiva es afectada por aspectos como barreras de entrada no convencionales (seguridad, sanidad), la centralización de las decisiones y la tendencia a sostener a toda costa la vigencia de los centros turísticos más consolidados. De este modo, en vez de corregir imperfecciones del mercado, la política pública ayuda a su consolidación y termina por construir barreras no convencionales de entrada para otros oferentes. 


\section{El tsunami que viene: el advenimiento de las políticas públicas orientadas}

a mejorar la experiencia del turista

\subsection{Escenarios de conflicto y negociación}

El tercer aspecto geopolítico que moldea la experiencia turística tiene que ver con los escenarios de conflicto y negociación en los destinos turísticos. Scarles y Lester (2016) sugieren que productores y consumidores participan y deben negociar la manera como se construyen las experiencias de los visitantes dando lugar a una pluralidad de interrelaciones, prácticas, procesos y actuaciones que sirven como mediadores de la relación entre los múltiples involucrados y el grado de involucramiento de un turista con el sitio que visita.

Para facilitar la construcción de experiencias, los distintos órdenes de gobierno deben lograr diseños de política y resolver en forma eficiente los conflictos de interés que enfrentan los visitantes a un sitio. Con este fin se requiere pasar de la provisión de condiciones para el consumo de bienes y servicios a la regulación de interacciones entre los involucrados en la vivencia de los visitantes. Los gobiernos locales deben avanzar en las siguientes tareas:

- Mejorar la calidad de gobierno y facilitar la innovación participativa en el diseño de políticas. La ausencia de corrupción, un sistema establecido donde predomina el imperio de la ley y la eficiencia burocrática (Lee, 2015) pueden ser favorables para la competitividad basada en experiencias. Las burocracias gubernamentales son útiles en esa tarea pero pueden generar problemas en aspectos como el registro de establecimientos de hospedaje (Filipe, 2014), la creación de oportunidades para los pobres en los destinos turísticos y la regulación de la prestación de los servicios (Ashley, Boyd y Goodwin, 2000). Jernsand, Kraff y Mossberg (2015) proponen que la innovación en la producción de experiencias constituye un proceso en espiral pues es posible aprender a usar algunas características de la experiencia para desarrollar nuevas y mejores experiencias.

- Abandonar el enfoque de políticas especializadas. La existencia de burocracias especializadas en turismo en los gobiernos locales, estatales y federales ha producido la ilusión de que es posible distribuir competencias y llegar con ello a políticas eficientes construidas bajo el principio de subsidiariedad. Sin embargo, los procesos de construcción de consensos son más amplios que eso y se complican por la dificultad para establecer las condiciones facilitadoras de experiencias. En este sentido, la existencia de instancias públicas especializadas puede ser un arma de doble filo, pues las agencias en cuestión pueden construir sus campos de acción y defenderlos de la intromisión de otras agencias. Para asegurar su misión y ampliar lo más posible su campo de acción, estas burocracias han construido una serie de barreras conceptuales y lineamientos que tratan de definir un campo de política pública especializada. Esta perspectiva que parece funcional para mantener o incluso expandir los cotos de poder público es en realidad fallida para crear competitividad en los destinos turísticos. 


\section{B. Verduzco Chávez}

- Desarrollar capacidades como facilitadores de diálogo. Esto incluye facilitar la interlocución entre interesados respecto a la construcción de experiencias. Los estudios recientes sugieren que las ciudades ganadoras en el mapa contemporáneo del turismo son aquellas donde líderes públicos y privados asumen funciones transformadoras y ayudan a crear condiciones para atender diferencias, facilitar la innovación y originar consensos en torno a temas controversiales que tienen que ver con la vida cotidiana de las ciudad turística y con el uso de sus recursos para producir un capital turístico (Verduzco, 2013).

- Facilitar la solución negociada de conflictos. Al describir el papel de los funcionarios públicos, sobre todo los locales, Elliot (1997) indica que a menudo su papel es gestionar los conflictos para reconciliar intereses e identifica diversas situaciones en las que esto es necesario. Por ejemplo, cuando emergen las controversias entre desarrolladores y comunidades, o se confrontan las necesidades de acumulación del capital y las racionalidades de los actores públicos, o hay conflictos entre diferentes agencias.

- Procurar consenso sobre portafolio de políticas. Determinar cuáles políticas pueden contribuir mejor a facilitar la construcción de experiencias de turistas en un destino es un problema de construcción de consenso entre múltiples actores representando a prestadores de servicios, organizaciones cívicas, asociaciones vecinales, expertos y una gran variedad de funcionarios públicos de distintos órdenes de gobierno. Una mala integración de políticas puede conducir a fallas en la procuración de objetivos y metas para resolver problemas complejos como la sustentabilidad del turismo (Hall, 2011). Para apoyar los procesos de construcción de experiencias, los gobiernos necesitan conformar portafolios de política que abarcan la dotación de infraestructura, la creación de plataformas tecnológicas, la seguridad pública, la regulación comercial, laboral y ambiental (entre otras), así como la vigilancia en materia de derechos de consumidor, política aduanera, política de comercio internacional.

En suma, la transición hacia el diseño de políticas públicas para mejorar la experiencia del turista atraviesa por decisiones que se toman en un contexto geopolítico en el cual participan una gran cantidad de actores que tienen intereses bien definidos y hacen demandas que deben gestionarse en procesos de negociación debidamente institucionalizados para dar certidumbre al proceso de producción de experiencias. Como se puede leer en el libro coordinado por Andrews (2014), la falta de acuerdos, la debilidad del Estado y distorsiones en las relaciones de poder existentes, pueden llegar a casos extremos de violencia, que si bien no eliminan del todo la vigencia de un destino turístico, crea un escenario de experiencias distinto que puede o no ser evaluado negativamente por los turistas dependiendo de sus propias construcciones subjetivas de la realidad. 


\section{Comentarios finales}

El estudio de la transición hacia políticas públicas orientadas a hacer posibles una gran diversidad de experiencias turísticas no tiene el propósito de explicar el éxito o fracaso de un destino turístico en particular, sino de explorar las posibilidades, retos y distorsiones que puede generar la adopción acrítica de esa opción de diseño de políticas. Interesados en incrementar la competitividad de destinos turísticos nacionales, regionales y locales, los gobiernos en distintas partes del mundo han incursionado en nuevas orientaciones de la política turística para dirigirla hacia la construcción de experiencias turísticas. En este ensayo se ha explorado esa posibilidad para lo cual se han identificado experiencias, avances y retos que plantea esa transición. La revisión realizada sugiere que ese tránsito es muy complicado e implica el abandono de enfoques tradicionales que impulsan la competitividad turística de los destinos con un enfoque imbuido de principios de política industrial que no es adecuado para la economía de la experiencia en la que se desarrollan las actividades turísticas.

En la marcha hacia las políticas facilitadoras de experiencias, los gobiernos tropezarán con diversas complicaciones. Aquí se han destacado algunas de corte metodológico, por ejemplo, la dificultad para medir cómo se construyen experiencias memorables, y otras de corte teórico-conceptual que tienen que ver con el inconveniente de lograr definiciones universales para un fenómeno que es por definición disperso, pues las experiencias no pueden ser completamente estandarizadas al ser coproducidas por los propios turistas.

Pero la existencia de dificultades para transitar en el sentido de las políticas públicas para la experiencia del turista no impedirá la multiplicación de experimentación con este enfoque. El apoyo de gobiernos nacionales y de organismos internacionales como la oCDE y la Organización Mundial del Turismo seguramente será crucial en esta tarea. La experiencia reciente en ese sentido ofrece algunas lecciones que ya pueden generar innovaciones en los distintos elementos del diseño de políticas públicas señalados aquí.

El gran reto para los diseñadores de políticas públicas orientadas a mejorar la experiencia de los visitantes es lograr avances sin trivializar la experiencia mediante esfuerzos simples de escenificación dirigidos al turismo de masas. Esa trayectoria ha demostrado consecuencias negativas tanto en la competitividad de los destinos como en la sustentabilidad de su desarrollo. Las teorías sobre la economía de la experiencia y sobre el papel que tienen la negociación y la participación de involucrados aportan guías importantes para avanzar en procesos verdaderamente innovadores de construcción de experiencias.

\section{Referencias}

Allen, G. y Brennan, F. (2004). Tourism in the New South Africa, Social Responsibility and the Tourist Experience. Londres, Inglaterra: I. B. Taouris. 


\section{B. Verduzco Chávez}

Álvarez, D. (2016). Las puertas del cielo. Aire, Aeroméxico, 38, pp. 82-88.

Andersen, L. F. (2015). The spatial and experimental dimensions of Coastal Zone Tourism in Denmark. En Anne Lorentzen, Karin Topsø Larsen y Lise Schrøder (eds.), Spatial Dynamics in the Experience Economy (pp. 174-190). Nueva York, Estados Unidos: Routledge.

Andrews, H. (2014). Tourism and Violence. Nueva York, Estados Unidos: Routledge.

Ashley, C., Boyd, Ch. y Goodwin, H. (2000). Pro-Poor Tourism: Putting poverty at the heart of the Tourism Agenda. Natural Resource Perspectives, 51. Recuperado de https:// www.odi.org/sites/odi.org.uk/files/odi-assets/publications-opinion-files/2861. pdf

Ashley, C., Brine, P. de, Lehr, A. y Wilde, H. (2007). The Role of the Tourism Sector in Expanding Economic Opportunity. Cambridge, Estados Unidos: Harvard University, The John F. Kennedy School of Government.

Ayuso, S. (2007). Comparing voluntary policy instruments for Sustainable Tourism: The experience of the Spanish Hotel Sector. Journal of Sustainable Tourism, 15(2), 144-159.

Beeton, S., Yamaura, T. y Seaton, Ph. (2016). The mediatisation of culture: Japanese contents tourism and pop culture. En J.-A. Lester y C. Scarles (eds.), Mediating the Tourist Experience, From Brochures to Virtual Encounters (pp. 139-154). Nueva York, Estados Unidos: Routledge.

Billie, T. (enero, 2010). The Nordic approach to the Experience Economy - does it make sense? (Creative Encounters, Working Paper 44). Copenhagen Business School.

Blanke, J. y Chiesa, Th. (2009). The Travel \& Tourism Competitiveness Report, 2009, Managing in a Time of Turbulence. Ginebra, Suiza: World Economic Forum.

Boyne, S., Hall, D. y Williams, F. (2003). Policy, support and promotion for Food-Related Tourism Initiative A Marketing Approach to Regional Development. Journal of Travel \& Tourism Marketing, 14(3-4), 131-154.

Bryant, J. et al. (septiembre de 2016). Secret San Diego. San Diego Magazine, 82-87.

Casellas, A. (2006). Las limitaciones del "modelo Barcelona". Una lectura desde urban regime analysis. Documents d'Análisi Geográfica, 48, 61-81.

Centre for Strategy \& Evaluation Services (2013). Final Report, Enhancing the Competitiveness of Tourism in the EU an Evaluation Approach to Establishing 20 Cases of Innovation and Good Practice. Sevenoaks, Reino Unido: Autor. Recuperado de http:// bit.ly/2bejUoe

Chronis, A. (2015). Moving bodies and the staging of the tourist experience. Annals of Tourism Research, 55, 124-140.

Cohen-Hattab, K. y Shoval, N. (2015). Tourism, Religion and Pilgrimage in Jerusalem. Nueva York, Estados Unidos: Routledge.

Cooper, Chris y Hall, Michael C. (2008). Contemporary Tourism: An International Approach, Londres: Butterworth-Heinemann.

Costa, C. C. S. (2012). Tourism Policy Instruments: An empirical analysis of Portuguese Local Governments. Revista Turismo \& Desenvolvimento, 17-18, 243-245.

Daher, R. F. (2007). Reconceptualizing tourism in the Middle East: Place, heritage, mobility and competitiveness. En R. F. Daher, Tourism in the Middle East: Continuity, Change, and Transformation (pp. 1-69). Cleveland, Estados Unidos: Channel View Publications. 


\section{El tsunami que viene: el advenimiento de las políticas públicas orientadas}

a mejorar la experiencia del turista

Dalonso, Y. S., Lourenco, J. M., Remoaldo, P. C. y Panosso Netto, A. (2014). Tourism experience, events and public policies. Annals of Tourism Research, 46, 181-184.

Donaire, J. A. y Galí, N. (2011). La imagen turística de Barcelona en la comunidad de Flickr. Cuadernos de Turismo, 27, 291-303.

Edensor, T. (2001). Performing tourism, staging tourism. Tourist Studies, 1(1), 59-81.

Elliot, J. (1997). Tourism, Politics and Public Sector Management. Nueva York, Estados Unidos: Routledge.

European Union (2011). Cities of Tomorrow, Challenges, Visions, Way Forward. Bruselas, Bélgica: Autor.

Fainstein, S. S., Hoffman, L. M. y Judd, D. R. (2003). Introduction. En L. M. Hoffman, S. S. Fainstein y D. R. Judd, Cities and Visitors, Regulating People, Markets and City Space. Nueva York, Estados Unidos: Wiley.

Fayos-Solá, E. (1996). Tourism policy: A midsummer night's dream? Tourism Management, 17(6), 405-412.

Filipe, J. A. (2014). Tourism destinations and local rental: A discussion around bureaucracy and anticommons. Algarve Case (Portugal). International Journal Latest Trends in Finance and Economic Sciences, 4(4), 821-830.

Fisker, J. K. (2015). Muncipalities as experiential stages in the new economy: Emerging practices in Frederikshavn, North Denmark. En Lorentzen Anne, Karin Topso Larsen y Lise Schroder (eds.), Spatial Dynamics in The Experience Economy (pp. 52-67). Nueva York, Estados Unidos: Routledge.

Franco, I. D. (2015). La cultura como estrategia de transformación y promoción urbana en Bogotá y Medellín. Revista de Geografía Norte Grande, 61, 25-43.

Frochot, I. y Batat, W. (2013). Marketing and Designing the Tourist Experience. Oxford, Inglaterra: Goodfellow Publishers Limited.

Fukuda Hayakawa, I. (enero-junio, 2010). Planeación urbana en Curitiba. Quivera, 12.

Hall, C. M. (2011). Policy learning and policy failure in sustainable tourism governance: From first- and second-order to third-order change? Journal of Sustainable Tourism, 19, 649-671.

Hazra, S., Fletcher, J. y Wilkes, K. (2014). An evaluation of power relationships among stakeholders in the tourism industry networks of Agra, India. Current Issues in Tourism. Recuperado de http://bit.ly/2gOqvZl

Henriksen, P. F. y Halkier, H. (2014). From local promotion towards regional tourism policies knowledge process and actor networks in North Jutland, Dennmark. En N. Kumral y A. Özlem Önder (eds.), Tourism, Regional Development and Public Policy (pp. 5-22). Nueva York, Estados Unidos: Routledge.

Hsu, T.-W., Inbakaran, R. y George, B. (2013). Understanding the concept of governance in tourism policy-making. International Journal of Economics and Business Research, 5(3), 319-336.

Jamal, T. y Lelo, L. (2011). Exploring the conceptual and analytical framing of dark tourism: From darkness to intentionality. En R. Sharpley y Ph. R. Stone, Tourist Experience, Contemporary Perspectives (pp. 20-28). Nueva York, Estados Unidos: Routledge.

Jernsand, E. M., Kraff, H. y Mossberg, L. (2015). Tourism experience innovation through design. Scandinavian Journal of Hospitality and Tourism, 15(1), 98-119. 


\section{B. Verduzco Chávez}

Jiricka, A., Salak, B., Eder, R., Arnberger, A. y Pröbstl, U. (2010) Energetic tourism: Exploring the experience quality of renewable energies as a new sustainable tourism market. WIT Transactions on Ecology and the Environment, 139, 55-68. Recuperado de http:/ / bit.ly/2bm3ibv.

Kavaratsis, M. (2017). The participatory place branding process for tourism: Linking visitors and residents through the City Brand. En N. Bellini y C. Pasquinelli (eds.), Tourism in the City: Towards an Integrative Agenda on Urban Tourism. Nueva York, Estados Unidos: Springer.

Kawato, Y. (2009). New Possibilities for Local Promotion through Tourism. Tokio, Japón: Institute for Comparative Studies in Local Governance (COSLOG), National Graduate Institute for Policy Studies (GRIPS). Recuperado de http://bit.ly/2bjAimr.

Keen, D. y Tucker, H. (2012). Future Spaces of Postcolonialism in Tourism. En J. Wilson (ed.), New Perspectives in Tourism Geographies (pp. 97-102). Nueva York, Estados Unidos: Routledge.

Kim, J.-H., Brent Ritchie, J. R. y McCormick, B. (2012). Development of a scale to measure memorable tourism experiences. Journal of Travel Research, 51(1), 12-25.

Laplante, M. (1996). L' expérience touristique contemporaine, Fondements sociaux et culturels. Quebec, Canadá: Presses de I'Université du Québec.

Lee, S. (2015). Quality of government and tourism destination competitiveness. Tourism Economics, 21(4), 881-888.

Lengkeek, J. (2002). A love affair with elsewhere: Love as a metaphor and paradigm for tourist longing. En G. M. S. Dann (ed.), The Tourist as a Metaphor of the Social World (pp. 189-208). Nueva York, Estados Unidos: CABI.

Ljunggren, E. (2012). Linking local food resources to high-quality restaurants in the Nordic Region. En OECD (ed.), Food and the Tourism Experience (pp. 63-74). The oECD Korea Workshop.

Lorentzen, A. y Jeannerat, H. (2013). Urban and regional studies in the experience economy: What kind of turn? European Urban and Regional Studies, 20(4), 363-369.

Mariani, M. M. (2016). The role of partnerships in staging tourist experiences, evidence from a festival. En M. M. Mariani, W. Czakon, D. Buhalis y O. Vitouladiti (eds.), Tourism Management, Marketing, and Development, Performance, Strategies, and Sustainability (pp. 173-193). Nueva York, Estados Unidos: Palgrave.

Mohammed, A. (2014). Tourism development policy versus practice in Ghana: The case of Lake Bosomtwe Basin. European Scientific Journal, 10(7), 308-334.

Molina Martínez, R., Ochoa Galván, M. y Gil Lafuente, A. M. (2014). Public policies and tourism marketing. An analysis of the competitiveness on tourism in Morelia, Mexico and Alcala de Henares, Spain. Procedia-Social and Behavioral Sciences, 148, 146152.

Moutinho, L., Ballantyne, R. y Rate, Sh. (2011). The new business environment and trends in tourism. En L. Moutinho (ed.), Strategic Management in Tourism (2 ed., pp. 1-19). Cambridge: $\mathrm{CABI}$ International.

Nordin, S. (2003). Tourism Clustering \& Innovation, Paths to Economic Growth \& Development. Östersund, Suecia: European Tourism Research Institute.

OECD (2016). OECD Tourism Trends and Policies 2016. París, Francia: Autor. Recuperado de http://bit.ly/2b2V1bX 
OECD (ed.). (2012). Food and the Tourism Experience. The OECD Korea Workshop.

Oh, H., Fiore, A. M. y Jeoung, M. (2007). Measuring experience economy concepts: Tourism applications. Journal of Travel Research, 46, 119-132.

Palomar Verea, J. (26 de noviembre de 2014). Lafayette/Chapultepec: por unas instrucciones de uso. El Informador. Recuperado de http://bit.ly/2cDGDLV

Pikkemaat, B., Peters, M., Bosberger, Ph. y Secco, M. (2009). The staging of experiences in Wine Region. Journal of Hospitality Marketing \& Management, 18(1-2), 237-253.

Pine, B. J. y Gilmore, J. H. (2011). The Experience Economy. Boston, Estados Unidos: Harvard Business Review Press.

Pine, B. J. II y Gilmore, J. H. (1998). Welcome to the experience economy. Harvard Business Review, 76(4), 97-105.

Porter, M. (noviembre, 2007). Clusters and Economic Policy: Aligning Public Policy with the New Economics of Competition (Isc White Paper). Harvard Business School. Recuperado de http://hbs.me/2b2tlkP

Quadri, D. L. (2012). An experience economy analysis of tourism development along the Chautauqua-Lake Erie Wine Trail, Graduate Theses and Dissertations (Paper 12443). Recuperado de http://lib.dr.iastate.edu/cgi/viewcontent.cgi?article=3450\&context=etd

Rech, M. F. (2015). A critical geopolitics of observant practice at British military airshows. Transactions of the Institute of British Geographers, 40, 536-548.

Redacción Proyecto Diez. (25 de abril de 2016). Saborea: caminar y comer en Guadalajara. Proyecto Diez. Recuperado de http://www.proyectodiez.mx/saborea-caminar-y-comer-en-guadalajara-lopez-cotilla/

Richards, G. y Wilson, J. (eds.). (2007). Tourism, creativity and development. Nueva York, Estados Unidos: Routledge.

Rodríguez, I., Williams, A. M. y Hall, M. C. (2014). Tourism innovation policy: Implementation and outcomes. Annals of Tourism Research, 49, 76-93.

Rowen, I. (2016). The geopolitics of tourism: Mobilities, territory, and protest in China, Taiwan and Hong Kong. Annals of the American Association of Geographers, 106(2), 385-393.

Saarinen, J. (2004). "Destinations in change". The transformation process of tourist destinations. Tourist Studies, 4(2), 161-179.

Salman, Saba (1 de octubre de 2008). Brand of gold. The Guardian. Recuperado de: http:/ / bit.ly/2wKXYf2.

Scarles, C. y Lester, J.-A. (2016). Mediating the tourist experience: From brochures to virtual encounters. En J.-A. Lester y C. Scarles, Mediating the Tourist Experience, From Brochures to Virtual Encounters (pp. 1-11). Nueva York, Estados Unidos: Routledge.

Schneider, A. L. e Ingram, H. (1997). Policy Design for Democracy. Lawrence, Estados Unidos: Kansas University Press.

Sharpley, R. y Stone, Ph. R. (2012). Expeirencing tourism, experiencing happiness? En R. Sharpley y Ph. R. Stone (eds.), Contemporary Tourism Experience, Concepts and Consequences (pp. 1-8). Nueva York, Estados Unidos: Routledge.

Sidali, K. L., Kastenholz, E. y Bianchi, R. (2013). Food tourism, niche markets and products in rural tourism: Combining the intimacy model and the experience economy as a rural development strategy. Journal of Sustainable Tourism. Recuperado de http:// 
dx.doi.org/10.1080/09669582.2013.836210

Sternberg, E. (1997). The iconography of the tourism experience. Annals of Tourism Research, 24(4), 951-969.

The Economist. (3 de enero de 2015). There's an app for that. The Economist. Recuperado de http:/ /econ.st/1y4UrmY

Tosun, C. (2000). Limits to community participation in the tourism development process in developing countries. Tourism Management, 21, 613-633.

UNEP (United Nations Environment Program) y wTo (World Tourism Organization). (2005). Making Tourism more Sustainable, a Guide for Policy Makers. París, Francia/Madrid, España: Autores. Recuperado de http://www.unep.fr/shared/publications/pdf/ DTIx0592xPA-TourismPolicyEN.pdf

Velasco González, M. (2011). Tourism policy. An autonomus policy arena. Cuadernos de Turismo, 27, 1171-1174.

Verduzco Chávez, B. (2013). Una Utopía Urbana (Im)Posible, la negociación infinita de planes de desarrollo urbano y prosperidad. Guadalajara, México: Universidad de Guadalajara.

Wang, X. y Meng, T. (2016). The research of customers satisfaction and public policy \& marketing design in special interest tourism-Macao culinary tourism. International Journal of Business and Management, 11(1), 124-135.

Yang, L. y Wall, G. (2014). Planning for Ethnic Tourism. Nueva York, Estados Unidos: Routledge. 